DOI: 10.12731/2227-930X-2019-3-43-49

УДК 004.421

\title{
СОЗДАНИЕ ФУНКЦИОНАЛЬНОЙ МОДЕЛИ ИНФОРМАЦИОННОЙ СИСТЕМЫ УПРАВЛЕНИЯ ДЛЯ АВТОМАТИЗАЦИИ ПРОЦЕССА РАСПРЕДЕЛЕНИЯ ЗАДАЧ ПРЕДПРИЯТИЯ
}

Еремина И.И., Иимурадова И.И., Лысанов Д.М.

Представленное исследование посвящено разработке автоматизированной информационной системы оценки эффективности маркетинговых мероприятий, выявлены особенностей разработки информационной системы эффективности проведения маркетинговых мероприятий, с учетом динамики влияния внешних и внутренних факторов средствами платформы 1С: Предприятие.

Ключевые слова: информачионная система; маркетинговые мероприятия; эффективность исследований.

\section{DEVELOPMENT OF A SYSTEM FOR EVALUATING MARKETING ACTIVITIES BY MEANS OF 1C: ENTERPRISE PLATFORM}

\section{Eremina I.I., Ishmuradova I.I., Lysanov D.M.}

The present study is devoted to the development of an automated information system for evaluating the effectiveness of marketing activities, the features of the development of an information system for the effectiveness of marketing activities, taking into account the dynamics of the influence of external and internal factors by means of the 1C: Enterprise platform.

Keywords: information system; marketing activities; research effectiveness.

\section{Введение}

Одной из наиболее важных проблем, возникающих в различных сферах человеческой деятельности, является проблема совер- 
шенствования управления. Эффективное управление базируется на оптимальном использовании ресурсов и грамотной комплексной оценке организации. При этом если на автоматизированном производстве производительность оборудования вычислима, то в компаниях, где эффективность работы характеризуется использованием человеческих ресурсов, всё не так просто. Если проанализировать вопрос о том, при каком условии можно достигнуть максимальной производительности труда, то очевидно, что это возможно только при правильном распределении внутренних задач в соответствии с возможностями персонала.

\section{Материалы и методы исследования}

Для разработки программного обеспечения, предназначенного для автоматизированного распределения задач была исследована работа сотрудников предприятий традиционного организационного устройства и определены особенности, на которые следует уделить особенное внимание в работе.

На основании результатов анализа создана таблица объектов, учитывающих особенности распределения задач и необходимые для корректной работы нового программного продукта. Данные представлены в таблице 1.

Таблицุа 1.

Элементы нового программного продукта

\begin{tabular}{|c|l|l|l|}
\hline № & $\begin{array}{l}\text { Наименование } \\
\text { объекта }\end{array}$ & \multicolumn{1}{|c|}{ Использование объекта } & \multicolumn{1}{|c|}{$\begin{array}{l}\text { Область рас- } \\
\text { пространения }\end{array}$} \\
\hline 1 & $\begin{array}{l}\text { Исполнитель- } \\
\text { ская дисциплина }\end{array}$ & $\begin{array}{l}\text { Объект определяет, какой процент } \\
\text { задач выполнялся сотрудником в } \\
\text { срок, а какие задачи выполнялись с } \\
\text { нарушением заданного срока. }\end{array}$ & $\begin{array}{l}\text { На конкретного } \\
\text { сотрудника }\end{array}$ \\
\hline 2 & $\begin{array}{l}\text { Загруженность } \\
\text { сотрудника }\end{array}$ & $\begin{array}{l}\text { Объект позволяет определить загруз- } \\
\text { ку сотрудника на заданный период } \\
\text { времени, позволяет решить, может ли } \\
\text { он взять новое поручение. }\end{array}$ & $\begin{array}{l}\text { На конкретного } \\
\text { сотрудника }\end{array}$ \\
\hline 3 & $\begin{array}{l}\text { Сертификация } \\
\text { сотрудника }\end{array}$ & $\begin{array}{l}\text { Объект определяет квалификацию } \\
\text { сотрудника и имеющиеся у него до- } \\
\text { кументы, подтверждающие профес- } \\
\text { сиональный уровень. }\end{array}$ & $\begin{array}{l}\text { На конкретного } \\
\text { сотрудника }\end{array}$ \\
\hline
\end{tabular}




\begin{tabular}{|c|c|c|c|}
\hline № & $\begin{array}{c}\text { Наименование } \\
\text { объекта }\end{array}$ & Использование объекта & $\begin{array}{l}\text { Область рас- } \\
\text { пространения }\end{array}$ \\
\hline 4 & $\begin{array}{l}\text { Профессиональ- } \\
\text { ная ориентация } \\
\text { сотрудника }\end{array}$ & $\begin{array}{l}\text { Объект определяет, является ли со- } \\
\text { трудник ориентированным на извест- } \\
\text { ные процедуры, либо ориентирован- } \\
\text { ным на новые возможности. }\end{array}$ & $\begin{array}{l}\text { На конкретного } \\
\text { сотрудника }\end{array}$ \\
\hline 5 & $\begin{array}{l}\text { Процессы с на- } \\
\text { рушением срока }\end{array}$ & $\begin{array}{l}\text { Объект определяет не выполненные } \\
\text { вовремя задачи. }\end{array}$ & На задачи \\
\hline 6 & $\begin{array}{l}\text { Задания на со- } \\
\text { гласование }\end{array}$ & $\begin{array}{l}\text { Объект определяет свободные задачи } \\
\text { на поручение. }\end{array}$ & На задачи \\
\hline 7 & $\begin{array}{l}\text { Динамика зада- } \\
\text { ний на согласо- } \\
\text { вание }\end{array}$ & $\begin{array}{l}\text { Объект определяет тенденцию актив- } \\
\text { ных задач и завершенных. }\end{array}$ & На задачи \\
\hline 8 & Вид задачи & $\begin{array}{l}\text { Объект определяет, какого рода задачи } \\
\text { ранее выполнялись и являются зада- } \\
\text { чами функционирования, а с какими } \\
\text { ответственный сталкивается впервые. }\end{array}$ & $\begin{array}{l}\text { На сотрудника } \\
\text { или подразде- } \\
\text { ление }\end{array}$ \\
\hline 9 & Статус & $\begin{array}{l}\text { Объект определяет, на каком этапе } \\
\text { выполнения находится задача. }\end{array}$ & На задачу \\
\hline 10 & Срок & $\begin{array}{l}\text { Объект задает установленный клиен- } \\
\text { том срок на выполнение. }\end{array}$ & На задачу \\
\hline 11 & Задержка & $\begin{array}{l}\text { Объект определяет нарушение срока } \\
\text { выполнения задачи. }\end{array}$ & На задачу \\
\hline 12 & $\begin{array}{l}\text { Отдел назначе- } \\
\text { ния }\end{array}$ & $\begin{array}{l}\text { Объект задает род работы для рас- } \\
\text { пределения между отделами. }\end{array}$ & $\begin{array}{l}\text { На подразде- } \\
\text { ление }\end{array}$ \\
\hline 13 & Ответственный & $\begin{array}{l}\text { Объект задает куратора для одного из } \\
\text { исполнителей задачи для обучения и } \\
\text { контроля качества работы с клиентом. }\end{array}$ & $\begin{array}{l}\text { На конкретного } \\
\text { сотрудника }\end{array}$ \\
\hline
\end{tabular}

Существует совокупность задач на выполнение, которые могут быть поставлены перед сотрудником или подразделением. Их можно разделить на два вида: известные, ранее отработанные задачи, они же «задачи функционирования», и ранее не решаемые в компании задачи, «задачи развития». С задачами функционирования лучше справляются специалисты, ориентированные на исполнение задач по отработанным механизмам. Они способны в процессе отработки задачи выявить «узкие места» и поставить в очередь на модернизацию. Благодаря сотрудникам данного типа в организации поддерживается устойчивость и стабильность работы. При этом правильным подходом при обнаружении возможности повышения 
производительности считается передача задачи для модернизации сотрудникам, ориентированным на решение задач развития. В таком случае задача каждого специалиста заключается в выполнении небольшого объема работ, направленного на достижение общего для компании результата. То есть задача в конкретном случае - это действие или средство, а не сама цель как таковая.

\section{Результаты исследования}

Основная функция системы заключается в формировании списка задач каждого сотрудника.

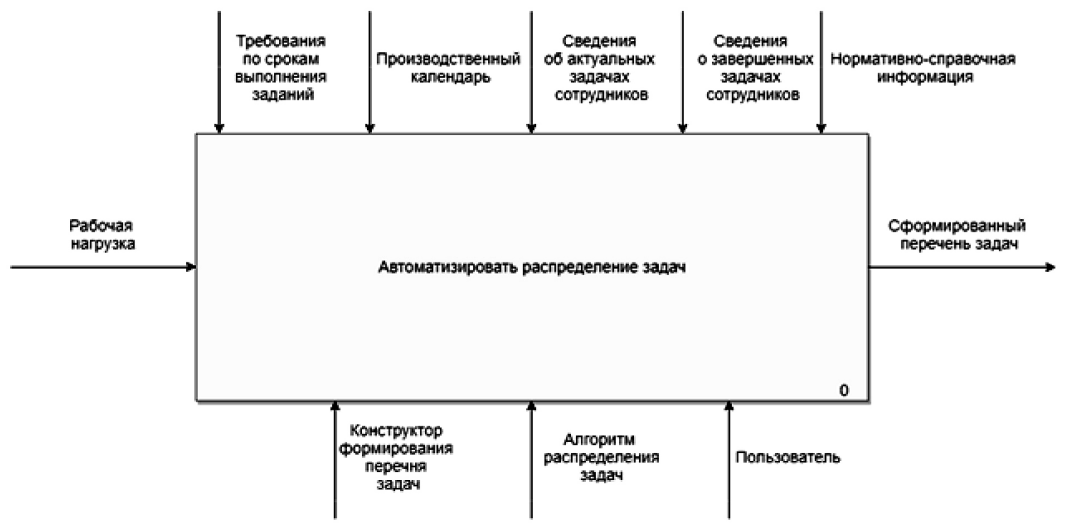

Рис. 1. Схема IDEF0 процесса «Автоматизировать распределение задач»

Процесс автоматизированного распределения задач для пользователя состоит из следующих этапов:

1. вносятся данные нормативно-справочной информации;

2. вносятся данные для мониторинга работы сотрудников;

3. устанавливается норма рабочего времени;

4. рассчитываются ограничения по рабочей нагрузке;

5. пополняется перечень задач на поручение;

6. после внесения необходимой информации, пользователь получает список задач на выполнение, сформированный автоматически; 
7. корректируется результат автоматического распределения для получения более эффективного варианта использования трудовых ресурсов.

Для графического представления описания процессов автоматизации формирования перечня задач созданы модели в нотации IDEF0 (Рисунок 1):

\section{Обсуждение}

Таким образом, на основании составленной математической модели, описанного алгоритма и сформулированного технического задания, приведенных в разделе Разработка математической модели и алгоритма распределения задач, был разработан прототип программного продукта для автоматизации распределения внутренних производственных задач предприятия с учетом специфики предметной области.

\section{Заключение}

Определены и рассчитаны универсальные критерии оценки эффективности деятельности сотрудников любого предприятия вне зависимости от внутренней организации и специфики предметной области.

Изучены существующие алгоритмы решения задач комбинаторной оптимизации в области математической оптимизации или исследовании операций. Составлена функциональная модель автоматизированного распределения поручений на примере тестовых данных.

\section{Список литературы}

1. Клюев И.П., Приходько В.А., Трофименко И.В. Распределение задач между сотрудниками, ориентированными на процедуры или новые возможности, как инструмент развития организации // Технико-экономический вестник «Русского Алюминия». 2012. № 22.

2. Lysanov D.M., Karamyshev A.N., Eremina I.I. Comparative evaluation of quality characteristics of process equipment // Astra Salvensis. 2017. T. 2017, pp. 217-224. 


\section{References}

1. Klyuev I.P., Prihod'ko V.A., Trofimenko I.V. Tekhniko-ekonomicheskij vestnik «Russkogo Alyuminiya». 2012. № 22.

2. Lysanov D.M., Karamyshev A.N., Eremina I.I. Comparative evaluation of quality characteristics of process equipment. Astra Salvensis. 2017. V. 2017, pp. 217-224.

\section{ДАННЫЕ ОБ АВТОРАХ}

Еремина Ирина Ильинична, кандидат педагогических наук, доцент

Набережночелнинский институт ФГАОУ ВО «Казанский федеральный университет»

проспект Сююмбике, 10а, г. Набережные Челны, 423812, Российская Федеращия ereminaii@yandex.ru

Ишмурадова Изида Илдаровна, кандидат экономических наук, доцент

Набережночелнинский институт ФГАОУ ВО «Казанский федеральный университет»

проспект Сююмбике, 10а, г. Набережные Челны, 423812, Российская Федерачия IIIshmuradova@kpfu.ru

Лысанов Денис Михайлович, кандидат технических наук, доцент Набережночелнинский институт ФГАОУ ВО «Казанский федеральный университет»

проспект Сююмбике, 10а, г. Набережные Челны, 423812, Российская Федерация kampi_ldm@mail.ru

DATA ABOUT THE AUTHORS

Eremina Irina Ilinichna, Associate Professor, Ph.D. in Education Naberezhnye Chelny Institute of Kazan Federal University 
10a, Syuyumbike Avenue, Naberezhnye Chelny, 423812, Russian Federation

ereminaii@yandex.ru

ORCID: 0000-0003-2333-3935

Ishmuradova Izida Ildarovna, Associate Professor, Ph.D. in Economics

Naberezhnye Chelny Institute of Kazan Federal University

10a, Syuyumbike Avenue, Naberezhnye Chelny, 423812, Russian Federation

IIIshmuradova@kpfu.ru

ORCID: 0000-0001-6307-8292

Lysanov Denis Mihailovich, Associate Professor, Ph.D. in Technical Sciences

Naberezhnye Chelny Institute of Kazan Federal University

10a, Syuyumbike Avenue, Naberezhnye Chelny, 423812, Russian Federation

kampi_ldm@mail.ru

ORCID: 0000-0002-0728-4435 